\title{
Periodontal disease in rheumatoid arthritis and Sjogren's syndrome: a modifiable risk factor for atherosclerosis?
}

\author{
Satish Rachapalli
}

Received: 14 July 2008 / Accepted: 7 September 2008 / Published online: 20 September 2008

(C) Springer-Verlag 2008

Autoimmune conditions like rheumatoid arthritis (RA) and Sjogren's syndrome (SS) are associated with accelerated atherosclerosis $[1,2]$. Although chronic inflammation may potentiate the effects of other well-known cardiovascular (CV) risk factors such as dyslipidemia, it is now clear that the disease itself represents an independent risk factor for $\mathrm{CV}$ disease not only because of chronic inflammatory process but also due to humoral and cell-mediated immune mechanisms. Patients with SS and RA are at a higher risk of having periodontitis (PD) than healthy controls and they have significantly increased periodontal attachment loss compared to controls [3, 4]. Micro vascular periodontal alterations may play a crucial part in the development of periodontal disease in RA patients and in those with SS, salivary B-cell activating factor (BAFF) is implicated in the pathogenesis [5, 6].

Interestingly, chronic inflammatory and microbial burden caused by the dental plaque in patients with PD is also thought to predispose to atherosclerotic process. There is emerging evidence that severe PD is associated with subclinical atherosclerosis in even young, otherwise systemically healthy patients [7]. From this available evidence, it can be assumed that RA and SS patients with PD are at a higher risk of developing premature atherosclerosis when compared to those without PD. We need more studies to confirm or refute this assumption and if this association is proven, an important sub group of these patients who needs aggressive modification of $\mathrm{CV}$ risk factors can be identified.

\section{References}

1. Gerli R, Sherer Y, Bocci EB, Vaudo G, Moscatelli S, Shoenfeld Y (2007) Precocious atherosclerosis in rheumatoid arthritis: role of traditional and disease-related cardiovascular risk factors. Ann N Y Acad Sci 1108:372-381. doi:10.1196/annals.1422.038

2. Vaudo G, Bocci EB, Shoenfeld Y, Schillaci G, Wu R, Del Papa N et al (2005) Precocious intima-media thickening in patients with primary Sjögren's syndrome. Arthritis Rheum 52(12):3890-3897. doi:10.1002/art.21475

3. Najera MP, al-Hashimi I, Plemons JM, Rivera-Hidalgo F, Rees TD, Haghighat $N$ et al (1997) Prevalence of periodontal disease in patients with Sjögren's syndrome. Oral Surg Oral Med Oral Pathol Oral Radiol Endod 83(4):453-457. doi:10.1016/S1079-2104(97) 90144-X

4. Pischon N, Pischon T, Kröger J, Gülmez E, Kleber BM, Bernimoulin JP et al (2008) Association among rheumatoid arthritis, oral hygiene, and periodontitis. J Periodontol 79(6):979-986. doi:10.1902/ jop.2008.070501

5. Scardina GA, Messina P (2007) Microvascular periodontal alterations: a possible relationship between periodontitis and rheumatoid arthritis. Clin Hemorheol Microcirc 37(3):229-235

6. Pers JO, d'Arbonneau F, Devauchelle-Pensec V, Saraux A, Pennec YL, Youinou P (2005) Is periodontal disease mediated by salivary BAFF in Sjögren's syndrome? Arthritis Rheum 52(8):2411-2414. doi:10.1002/art.21205

7. Cairo F, Castellani S, Gori AM, Nieri M, Baldelli G, Abbate R et al (2008) Severe periodontitis in young adults is associated with sub-clinical atherosclerosis. J Clin Periodontol 35:465-472. doi:10. 1111/j.1600-051X.2008.01228.x 